\title{
Symposia on behavioral economics of the COVID-19 pandemic
}

\author{
(c) Economic Science Association 2020
}

Experimental Economics and the Journal of the Economic Science Association will publish parallel Symposia focused on COVID-19.

Topics could include various methodological issues associated with running experiments during a pandemic, some new software (provided it is tested/validated), natural experiments involving the pandemic, effects on behavior, productivity, diversity etc., and experimental evaluations of epidemiological models and their assumptions.

In line with the scopes and aims of the respective journals, longer articles and those addressing fundamental research questions should be directed to Experimental Economics, while shorter articles and replications should be directed to JESA. The editors of Experimental Economics can suggest a transfer to JESA if they see this as a better fit.

At JESA, we particularly welcome replications of well-known experiments in non-laboratory settings, including failed replications, as well as papers discussing the problems that might arise when transiting to a non-laboratory environment, and the issue of linking data collected in the laboratory, online and in the field.

The deadline for submission is 15 th December 2020. However, we welcome submissions at any point to the submission deadline and they will be evaluated as soon as they are submitted and published online as soon as they are accepted. We plan the Symposia to appear in an issue in late 2021/early 2022 and to consist of 6-7 papers.

Papers should be submitted using the Experimental Economics and JESA submission portals, selecting the Symposium as the submission type.

Please do not hesitate to contact any of the editors should you have questions regarding these Symposia.

We look forward to reading your manuscripts

Sincerely,

Editors

Experimental Economics and JESA

Publisher's Note Springer Nature remains neutral with regard to jurisdictional claims in published maps and institutional affiliations. 